\title{
Atypical Fulminant Rickettsia rickettsii Infection (Brazilian Spotted Fever) Presenting as Septic Shock and Adult Respiratory Distress Syndrome
}

Paulo Sérgio Gonçalves da Costa, Marcos Emilio Brigatte, Edmilton Pereira de Almeida and Lena Márcia de Carvalho Valle

\author{
Federal University of Minas Gerais, Belo \\ Horizonte, MG; Barbacena Medical School, \\ MG; Monte Sinai Hospital, Juiz de Fora, \\ MG; Santa Casa de Misericórdia Hospital, \\ Juiz de Fora, MG; Faculty of Medicine, \\ University of São Paulo Brazil, São Paulo, \\ SP, Brazil
}

\begin{abstract}
Brazilian spotted fever, caused by Rickettsia rickettsii, has been increasingly reported in Brazil especially in the southeastern states. The severe and fulminant forms of the disease are not unusual but most of the reported fatal cases have shown some typical clinical clue, which leads the attending physician to a correct diagnosis. We report a probable case of atypical fulminant Brazilian spotted fever that presented full-blown septic shock associated with Adult Respiratory Distress Syndrome (ARDS) and delayed uncharacteristic rash with an over four-fold increase in reciprocal IgM, but not IgG titer against Rickettsia rickettsii. Brazilian practitioners should be aware of the possibility of Brazilian spotted fever as a cause of fulminant primary sepsis with ARDS; improved laboratory methods are necessary for the rapid diagnosis of such cases.

Key Words: Rickettsia rickettsii, Brazilian spotted fever, sepsis, ARDS.
\end{abstract}

Rickettsia rickettsii infections can cause a wide range of clinical manifestations, ranging from asymptomatic or mild febrile illness to overwhelming and fatal disease [1-6]. The classical symptomatic presentation of the disease is the so called "Spotted fever" which typically evolves from an initial unspecific clinical picture of fever, headache and myalgia to the development of a purpuric palpable rash, especially on the hands and feet; these are the principal symptoms for a differential diagnosis [1,4-6].

Mild and atypical cases have usually been identified during ongoing outbreaks or retrospectively, in seroepidemiological studies $[1,6,7]$.

Received on 9 October 2001; revised 15 February 2002. Address for correspondence: Dr. Paulo Sérgio Gonçalves da Costa. Rua Delfim Moreira, 181-902, Zip code: 36010-570, Juiz de Fora, Minas Gerais, Brazil. Phone: (55 32) 9987-9514/32175716. Fax: (55 32) 3239-4157.E-mail :psgcosta@fusoes.com.br

The Brazilian Journal of Infectious Diseases 2002;6(2):91-96 (C) 2002 by The Brazilian Journal of Infectious Diseases and Contexto Publishing. All rights reserved.

$1413-8670$
Failure in diagnosis and delayed therapy have contributed to hidden mortality, which is commonly associated with Rickettsia rickettsii infections [6,10]. This scenario is most frequently a result of atypical fulminant forms of the disease $[1,6,10]$ and a lack of physician knowledge about the disease [6,9], which is exacerbated by the difficulty of adequate confirmatory laboratory tests during its acute phase [10-12].

Rickettsial diseases have been considered emerging zoonoses worldwide $[13,14]$ so it is important to improve knowledge of the septic fulminant forms of Rickettsia rickettsii infection, which should no longer be classified as a rare disease in Brazil.

\section{Case report}

A 14 year-old boy was admitted to the hospital with a history of fever, myalgias and headache during the previous 3 days. He took first generation cephalosporin orally, without improvement and his clinical picture deteriorated with the appearance of dyspneia and an increased respiratory rate. 
His past medical history was unremarkable and there was a report of strenuous physical effort 2 days before his illness. He denied illegal drug use or exposure to known infected people. At first he denied tick exposure but it was latter discovered that although he resided in an urban area he occasionally was bitten by ticks, especially when riding street horses.

His physical examination during admission was unremarkable except for the fever $\left(39^{\circ} \mathrm{C}\right)$ and other signs of Systemic Inflammatory Response Syndrome (SIRS), including increased respiratory (28/min) and heart (130/min) rates. A chest X-ray taken at admission was normal. He was given intravenous amoxicillinclavulanic acid plus amikacin and gatifloxacin, after blood cultures were taken, but 24 hours later he developed clinical and laboratory signs of acute respiratory insufficiency. The patient was transferred to the intensive care unit where a new chest $x$ ray showed extensive bilateral alveolointerstitial infiltrate (Figure 1-A), compatible with Adult Respiratory Distress Syndrome (ARDS).

The total white blood cell count was 10,400 per $\mathrm{mm}^{3}$ (4\% metamielocytes, 36\% banded forms, $54 \%$ segmented, $4 \%$ lymphocytes, $2 \%$ monocytes) and the platelet count was 52,000. The arterial blood gases had $\mathrm{pH}$ of 7.39, a $\mathrm{PO}_{2}$ of $77 \mathrm{mmHg}$, a $\mathrm{PCO}_{2}$ of 26 $\mathrm{mmHg}$ and $16 \mathrm{mmol} / 1$ total $\mathrm{CO}_{2}$. The patient had normal levels of amylase, glucose and BUN but increased levels ofALT (180 U/1), AST (352 U/1), GGT (786 U/1) and direct bilirubin $(4.5 \mathrm{mg} / \mathrm{dl})$. CPK levels of 7,206U/1 and LDH levels of 1,143 U/1 were compatible with rhabdomyolisis. At this time an abdominal computerized tomography revealed a small amount of free fluid in the peritoneal cavity. Consequently an emergency videolaparoscopy was made, that was unremarkable except for diffuse peritoneal petechiae and a small amount of acellular sterile fluid. The echocardiogram was normal.

Respiratory support was started and vancomycin plus chloranphenicol was added to the previous antimicrobial scheme.

A tiny purpuric rash was then observed on the trunk and especially on the face (Figure 1-B and C), but despite all additional measures that included a Swan
Ganz catheter for measurement of pulmonary capillary wedge pressure, cardiac output and systemic vascular resistance, crystalloid infusion, blood transfusions and different vasoactive inotropic drugs he evolved to a refractive shock and Multiple Organ Dysfunction Syndrome (MODS). At a given moment he had a $\mathrm{PaO}_{2} / \mathrm{FIO}_{2}$ ratio of 164 and a slight increase in PWAP (28) but no other evidence of cardiac dysfunction. He developed severe renal insufficiency that evolved to a complete shutdown and disseminated intravascular coagulation (DIC) with D-dimer levels of 8,331.90 and refractive mucosal bleeding diathesis. The patient eventually died on day 6 of hospitalization. All blood cultures as well as serological tests for HIV, Salmonella typhi, leptospirosis (IgM capture assay), hantaviruses, Chlamydia psittaci IgG/IgM, Legionella pneumophila $\mathrm{IgG} / \mathrm{IgM}$, brucelosis, dengue $\mathrm{IgG} / \mathrm{IgM}$, toxoplasmosis $\mathrm{IgG/IgM} \mathrm{and} \mathrm{Mycoplasma}$ pneumoniae $\mathrm{IgG} / \mathrm{IgM}$ resulted negative or noncompatible with recent infection.

Given the absence of an etiological diagnosis for septic shock, serum samples were continuously collected and stored on a daily basis for further tests, including for rickettisal diseases as part of a current protocol in this setting. No necropsy was performed.

Serological test for Rickettsial diseases. The serological tests for rickettsial diseases were performed by the microimmunofluorescence technique (IFA), as described elsewhere $[15,16]$, with antigens of Rickettsia rickettsii (Sheila Smith strain), Rickettsia typhi (Willmington strain), Coxiella burnetii (Nine Mile strain). Phase I and phase II and positive and negative control sera were provided by the Viral and Rickettsial Branch of CDC Atlanta USA. Fluoresceinconjugated goat anti-human IgG and anti-human IgM (Biolab Merrieux) were used for antibody detection.

All sera were initially screened at a dilution of $1 / 8$ and the positive tests were subsequently titered to an end point, which was considered the final titer. The slides were read blindly and a fluorescence of at least ++ was required for positivity. No rheumatoid factor activity was found in any of the samples. All samples were positive for IgM but not IgG against Rickettsia 
Figure 1. Chest $X$-ray showing diffuse pulmonary edema $(A)$ in a severely ill septic patient with tiny purpuric rash on the trunk and face (B); his amplified facial purpura (C)

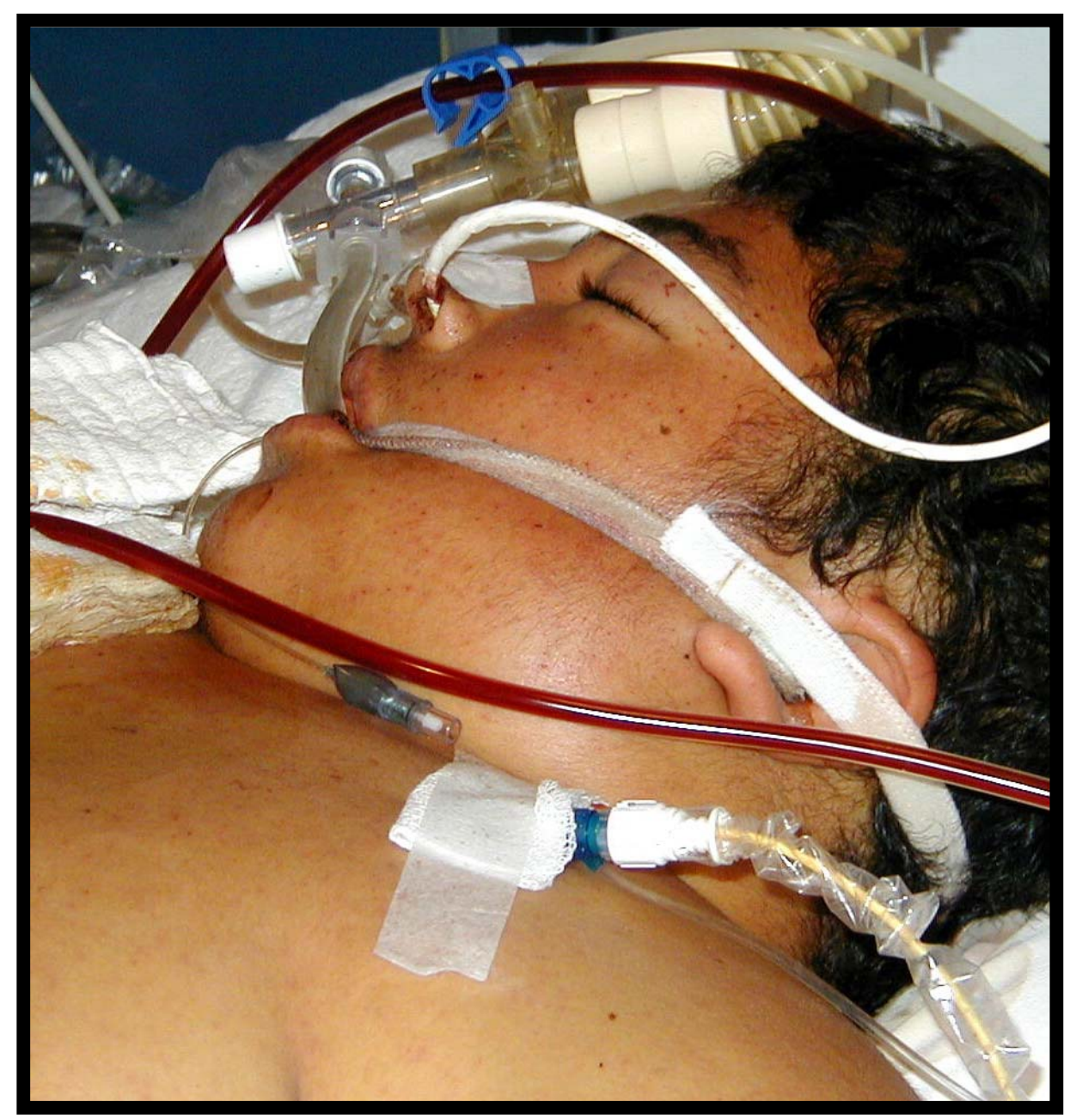

rickettsii in the following pattern: day 1 and $2: \operatorname{IgM}$ positive 1/32; days 3, 4 and 5: 1/64 and day 6: 1/256. All samples but one (day 6), which was Rickettsia typhi IgM positive at $1 / 16$ titer, were $\operatorname{IgM}$ and $\operatorname{IgG}$ negative for all other rickettsial antigens.

\section{Discussion}

Rickettsia rickettsii is a small pleomorphic Gramnegative obligate intracellular parasitic organism capable of infecting endothelial cells in both humans and animals
[1,4-6]. In South America natural transmission involves tick vectors, especially Amblyomma species [6,1720]. As vertical transmission occurs, the juvenile (nymphs) infected ticks are theoretically more dangerous than adult infected ticks since they usually attack in greater numbers, are more likely to remain unrecognized on the victim's body and have higher rates of infection [21]. Until recently, this disease was considered a medical rarity in restricted areas of São Paulo state [20], and despite the very appropriate ecological conditions for large tick populations in Brazil $[18,19]$ it has not attracted sufficient medical attention, 
being hardly ever thought of in clinical diagnosis [22]. Recently the infection has been more frequently reported in Minas Gerais state [23,24] with approximately 25 cases/year [25]. However rickettsial disease hadn't been reported in our region (Zona da Mata) until 1995 when 3 autochthone cases were identified, 2 of them in Piau County (3,000 inhabitants) [26]. After that, another 4 cases were identified ( 2 in Juiz de Fora city, 1 in Simão Pereira County and 1in Piau County). In this latter, small rural community the seroprevalence ranges from 1 to $2 \%$ (data not shown).

The clinical spectrum of the disease is quite variable, from asymptomatic to fulminant forms, but almost only diagnosed after the typical purpuric rash appearance in a patient with a history of tick bites $[1,6,7]$.

Unfortunately only $3 \%$ to $18 \%$ of the patients present rash and fever and report tick exposure on their first visit, making the disease potentially undiagnosed and untreated [6,7]. Some cases never develop rash (spotless or almost spotless) making the condition truly "a wolf in sheep's clothing" according to Sexton et al [27]. In fact, many reported outbreaks have been preceded by unexplained deaths $[26,28]$ and hidden mortality is a well-known circumstance of this disease [10] and the case reported here illustrates this picture. The most accurate method for the diagnosis of Rickettsia rickettsii infection is the identification of the agent, either by PCR, cell culture or by immunostaining in tissue specimens [1,5,29], since the old, dangerous techniques using animal inoculation have been progressively abandoned [5]. However, the detection of antibody to Rickettsia rickettsii by IFA remains the best-recognized and most available laboratory method to diagnose Brazilian Spotted Fever $[1,5,10]$. This patient had Rickettsia rickettsii infection according to the current criteria for its serological diagnosis [5-7,10], since a over four-fold increase in IgM or IgG antibody titer or titers over $1 / 32$ for IgM and 1/64 for IgG are considered diagnostic for acute infection $[1,30,31]$. The absence of IgG antibody doesn't preclude this diagnosis and is compatible with the $1^{\text {st }}$ week of disease, when only $25 \%$ show seropositivity $[1,6,7,10,30]$.
The specificity of anti-Rickettsia rickettsii antibodies has been considered high even though $[15,16,31]$ there is a remote possibility of crossreactivity with other rickettsial species [32], as was observed for Rickettsia typhi in this case and with non-rickettsial agents [33-36]. Since the agent was not isolated there is a theoretical possibility of another rickettsial agent infection in this case and in this scenario it is important to keep in mind the crossreactivity between Rickettsia rickettsii and the newly discovered Rickettsia felis already described in Minas Gerais state [37]. No cross-reactivity was detected in the patient's serum to Coxiella burnetii and Rickettsia typhi in all but one sample which showed IgM reactivity to the latter antigen, and even without testing all other rickettsial agents, this finding together with the striking antibody titer increase and the absence of a rheumatoid factor, argues against that possibility.

The patient apparently did not respond to the initial therapy, especially the gatifloxacin that is supposed to be effective against rickettsial infections [6]. The effectiveness of this drug however needs to be confirmed in clinical trials [6] and the fulminant clinical course itself with rapid evolution to ARDS could explain this outcome, independent of drug efficacy.

Bilateral alveolointerstitial infiltrate and severe hypoxemia with $\mathrm{PaO}_{2} / \mathrm{FIO}_{2}$ no higher than 200 together with consistent findings from catheterization of the right side of the heart were compatible with ARDS [38], despite high pulmonary wedge pressure detected after MODS installation.

Although pulmonary involvement has been frequently reported in severe human Rickettsia rickettsii infection, this disease is not commonly a cause of ARDS [6,39], which was quite premature and actually preceded the septic shock in this case. This suggests a need for inclusion of Rickettsia rickettsii infection among unexplained causes of ARDS, as was recently established for Hantavirus infections [40].

In conclusion, human Rickettsia rickettsi infections should be included among the known causes of primary sepsis with ARDS and a rather atypical clinical course together with a lack of epidemiological 
data should not preclude this kind of diagnosis. Physicians must be made aware of this life-threatening entity, considering the imperative need for adequate anti-rickettsial therapy.

\section{Acknowledgments}

We are thankful to Drs James G. Olson, Gregory A. Dash, James E. Childs and Russell L. Regnery from the Viral and Rickettsial branch of CDC Atlanta GA USA for providing the rickettsial antigens, Dirceu Bartolomeu Greco MD PhD from the Postgraduate course of Tropical Medicine- UFMG-Belo Horizonte, MG, Brazil for critical review of this article and Robert Corley for the English review.

\section{References}

1. Anonymous. Rocky Mountain spotted fever. www.cdc.gov/ncidod/dvrd/rmsf/ index.htm august 2000.

2. Marx R.S., McCall C.E., Abramson J.S., Harlan J.E. Rocky Mountain spotted fever. Serological evidence of previous subclinical infection in children. Am J Dis Child 1982; 136 :16-8.

3. Gonçalves A.J.R., Lopes P.F.A., Melo J.C.P. et al Rickettsioses a propósito de 4 casos diagnosticados no Rio de Janeiro de febre maculosa Folha Medica (Br) 1981; 82:127-34.

4. Gonçalves A.J.R., Pinto A..M..M., Melo J.C.P., et al Febre maculosa brasileira Considerações relativas a dois casos da cidade do Rio de Janeiro. Jornal Brasileiro de Medicina (JBM) 1981;41:55-7.

5. Walker D.H., Raoult D. Rickettsia rickettsii and other spotted fever group rickettsiae (Rocky Mountain spotted fever and other spotted fevers). In: Mandell, G.L., Bennett, J.E., and Dolin, R., Eds. Principles and Practice of Infectious Disease. , Churchill Livingston, New York, N.Y.1995.

6. Walker D.H., Sexton D. J. Rickettsia rickettsii. In: Yu, V.L., Merigan, T.C., and Barriere, S.L. (Eds). Antimicrobial Therapy and Vaccines. Williams and Wilkins, Baltimore, Md. 1999.

7. Anonymous. Consequence of delayed diagnosis of rocky mountain spotted fever in children in West Virginia, Michingan, Tennessee, and Oklahoma. MMWR 2000;49:885-8.
8. Campos E.P., Meira D.A. Febre maculosa apresentação de um caso clínico. Rev Inst Med Trop 1982;15:121-4.

9. Sarov B., Galil A., Sikuler P., et al. Prospective study on symptomatic versus asymptomatic infections and serological response to spotted fever group rickettsiae in two rural sites in the Negev (southern Israel). An N Y Acad Sci 1990;590:243-5.

10. Paddock C.D., Greer P.W., Ferebee T.L., et al. Hidden mortality attributable to Rocky Mountain spotted fever: immunohistochemical detection of fatal, serologically unconfirmed disease. J Infect Dis 1999; 179:1469-76.

11. Suto T. [Serologic diagnosis of rickettsial diseases-early and rapid diagnosis of great importance] Nippon Rinsho 1990;48Suppl:440-3.

12. Young R.P., Ip M., Bassett D.C. Fatal rickettsial meningitis in Hong Kong: a need for rapid laboratory diagnosis. Scand J Infect Dis 1995;27:527-8.

13. Childs J., Shope R.E., Fish D., et al. Emerging Zoonosis Emerg Infect Dis 1998;4:453-4.

14. Raoult D., Roux V. Rickettsiosis as paradigms of new or emerging infectious diseases. Clin Microbiol Rev 1997;10:694-719.

15. Philip R.N., Casper E.A., Ormsbee R.A., et al. Microimmunofluorescence test for the serological study of Rocky Mountain spotted fever and typhus. J Clin Microbiol 1976;3:51-61.

16. Newhouse V.F., Shepard C.C., Redus M.D., et al. A comparison of the complement fixation, indirect fluorescent antibody and microagglutination tests for the serological diagnosis of rickettsial diseases. Am J Trop Med Hygiene 1979;28:387-95.

17. Azad A.F., Beard C.B. Rickettsial pathogens and their arthropod vectors. Emerging Infect Dis 1998;4:179-82.

18. de Lemos E.R., Melles H.H., Colombo S., et al. Primary isolation of spotted fever group rickettsiae from Amblyomma cooperi collected from Hydrochaeris hydrochaeris in Brazil. Mem Inst Oswaldo Cruz 1996;91:273-5.

19. de Lemos E.R., Machado R.D., Pires F. D., et al. Rickettsiaeinfected ticks in an endemic area of spotted fever in the State of Minas Gerais, Brazil. Mem Inst Oswaldo Cruz 1997;92:477-81.

20. Rosenthal C. Riquetsioses In: Amato Neto (ed) Doenças Transmissíveis. Savier, São Paulo,1989.

21. Magnarelli L.A., Anderson J.F., Burgdofer W., et al. Spotted fever group rickettsiae in immature and adult ticks (Acari: Ixodidae) from focus of Rocky Mountain spotted fever in Connecticut. Can J Microbiol 1985;31:1131-5.

22. Anonymous Global surveillance of rickettsial diseases: memorandum from a WHO meeting. Bull World Health Organ 1993;71:293-6. 
23. de Lemos E.R., Machado R.D., Coura J.R. Rocky Mountain spotted fever in an endemic area in Minas Gerais, Brazil. Mem Inst Oswaldo Cruz 1994;89:497-501.

24. Souza M.A.A., Paula A.B., Primo J.D.A., et al. Febre maculosa em Virginópolis Minas Gerais VI Congresso Brasileiro de Infectologia, 1991.

25. Anônimo Boletim Informativo FUNED (Fundação Ezequiel Dias) MG Numero de casos de Febre Maculosa, 2000.

26. Hallack K.A., Cunha R.M.C., Roland R.K., et al. Ocorrência de casos de febre maculosa na zona da mata mineira abstract 232 Anais IX Congresso Brasileiro de Infectologia, Recife, 1996.

27. Sexton D.J., Corey G.R. Rocky mountain "spotless" or "almost spotless" fever: a wolf in sheep's clothing. Clin Infect Dis 1992; 15:439.

28. Sexton D.J., Muniz M., Corey G.R., et al. Brazilian spotted fever in Espirito Santo, Brazil: description of a focus of infection in a new endemic region. Am J Trop Med Hyg 1993;49(2):222-6.

29. Melles H.H.B., Colombo S., Silva M.V. Febre maculosa:isolamento de rickettsia em amostra de biopsia de pele. Rev Inst Méd Trop São Paulo 1992;34:37-41.

30. Clements M.L., Dumler J.S., Fiset P., et al. Serodiagnosis of Rocky Mountain spotted fever: comparison of $\operatorname{IgM}$ and IgG enzyme-linked immunosorbent assays and indirect fluorescent antibody test. J Infect Dis 1983; 148:876-80.

31. Hays P. Rocky Mountain spotted fever in children in Kansas: The diagnostic value of an IgM-specific immunofluorescence assay. J Infect Dis 1985; $151: 369-70$.

32. Hechemy K.E., Raoult D., Fox J., et al. Cross-reaction of immune sera from patients with rickettsial diseases. J Med Microbiol 1989;29:199-202.

33. Raoult D., Dasch G.A. Immunoblot cross-reactions among Rickettsia, Proteus spp. and Legionella spp. in patients with Mediterranean spotted fever. FEMS Immunol Med Microbiol 1995; 11:13-8.

34. La Scola B., Raoult D. Serological cross-reactions between Bartonella quintana, Bartonella henselae, and Coxiella burnetii. J Clin Microbiol 1996;34:2270-4.

35. Maurin M., Eb F., Etienne J., Raoult D. Serological crossreactions between Bartonella and Chlamydia species: implications for diagnosis. J Clin Microbiol 1997;35:2283-7.

36. Musso D., Raoult D. Serological cross-reactions between Coxiella burnetii and Legionella micdadei. Clin Diagn Lab Immunol 1997;4:208-12.

37. Raoult D., La Scola B., Enea M., et al. A flea associated rickettsia pathogenic for humans Emerg Infect Dis 2001; 7:73-81.

38. Bone R. The pathogenesis of sepsis. Ann Int Med 1991; 115:457-69.
39. Walker D., Crawford C.G., Cain B.G. Rickettsial infection of the pulmonary microcirculation: The basis for interstitial pneumonitis in Rocky Mountain spotted fever. Human Pathol 1980; 11:263-72.

40. Sestaro C., Fernandes S.R.C., Vilela R.S., Henriques W.N. Hantavirus pulmonary syndrome: an alert to Latin America countries. Braz J Infect Dis 1999;3:203-14. 